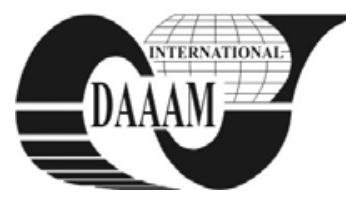

Annals of DAAAM for 2011 \& Proceedings of the 22nd International DAAAM Symposium, Volume 22, No. 1, ISSN $1726-9679$ ISBN 978-3-901509-83-4, Editor B. Katalinic, Published by DAAAM International, Vienna, Austria, EU, 2011 Make Harmony between Technology and Nature, and Your Mind will Fly Free as a Bird Annals \& Proceedings of DAAAM International 2011

\title{
DRILLING OF BIOCOMPOSITE POLYMERIC PRODUCTS
}

\section{MURAR, D[iana] A[nca]; OPRAN, C[onstantin] \& BIVOLARU, C[atalina] F[lorentina]}

\begin{abstract}
Drilling of biocomposite polymeric products is a key operation when it comes to assembly. When drilling into such materials, many problems may appear, such as high axial forces, very high temperatures at the contact zone between the tool and the material, delaminating of the material, tool wear etc. The result of research on the variation of cutting force when drilling are being presented in this paper; during the experiments, two types of biocomposite polymeric products reinforced with wood fibre were used.

Key words: biocomposites, cutting, drilling, machining
\end{abstract}

\section{INTRODUCTION}

Biocomposite polymeric products are used extensively because of their higher strength to weight ratios and, when compared to metals, offer new opportunities for design. However, being non-homogenous, anisotropic and reinforced with very soft fibers, these materials are difficult to machine.

Biocomposite polymeric materials possess peculiar characteristics that govern behavior during machining. Drilling is the most frequently employed operation of secondary machining for fiber-reinforced materials owing to the need for structure joining.

Biocomposite polymeric products present a real scientific and technical interest, which justifies the development of research in this field, as well as the increase in the production of such materials.

Biocomposite polymeric products have become indispensable for the development of some top fields like: aerospace, constructions, automotive.

For this research, we used two types of biocomposites polymer and namely one polymeric biocomposites reinforced with oak particles and second bicomposites polymeric reinforced with particles of pine wood.

\section{METHOD, MEANS AND CONDITIONS FOR THE DRILLING WHEN DETERMINING THE FORCES}

The devices used for the research on the methods of determining the machining indicators:

Drilling machine used: First MCV 300

- Power of work: $1.2 \mathrm{KW}$;

- Gamma of rotations: 1-10000 mm/min;

- Maximum speed: 8000 rpm/10000 rpm. Specifications drilling tools:

The specialty literature present curved drills as tools used when drilling biocomposite polymeric materials. From the catalogs of companies that produce drills, the following have been chosen for laboratory experiments:

-drills: $\Phi 10$, made by SANDVIK, (figure 1).

Material properties are the following:

Materials of which the biocomposite polymeric material is made of: -reinforcement element: particles of oak wood, particles of pine wood.

- matrix: polyester resin AROPOL S 599.

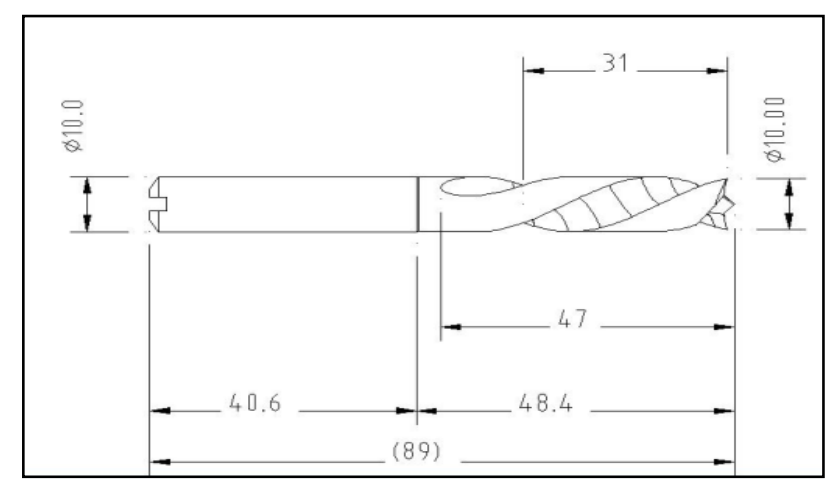

Fig. 1. Drill made by SANDVIK Coromat

Stand for the study of cutting forces during the drilling process for materials made by biocomposites polymeric (Figure 2) is made by: CNC processing center FIRST MCV 300 (1), cell mass Kistler (2), computerized data acquisition systems (3).

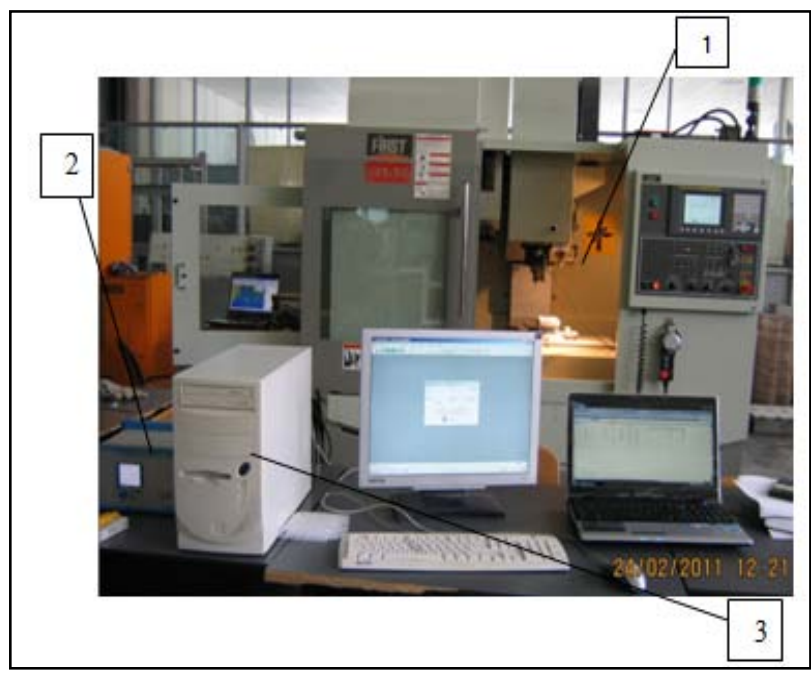

Fig. 2. The registration system

\section{EXPERIMENTAL RESULTS AND DATA PROCESSING}

Following these experiments were obtained a total of 36 data files, every data files for for each process performed.

In all cases, the graphs of variation of forces are properly the plan of experiments (Table 1) manufactured from biocomposites polymer reinforced with particles of oak and manufactured from biocomposites polymer reinforced with particles of pine (Table 2). 


\begin{tabular}{|c|c|c|c|c|}
\hline$D$ & $f$ & $n$ & $V c$ & $V f$ \\
\hline$[\mathrm{mm}]$ & {$[\mathrm{mm} / \mathrm{rot}]$} & {$[\mathrm{rot} / \mathrm{min}]$} & {$[\mathrm{m} / \mathrm{min}]$} & {$[\mathrm{mm} / \mathrm{min}]$} \\
\hline 10.00 & 0.02 & 3000 & 94.2 & 60 \\
\hline 10.00 & 0.05 & 3000 & 94.2 & 150 \\
\hline 10.00 & 0.08 & 3000 & 94.2 & 240 \\
\hline 10.00 & 0.1 & 3000 & 94.2 & 300 \\
\hline 10.00 & 0.12 & 3000 & 94.2 & 360 \\
\hline 10.00 & 0.15 & 3000 & 94.2 & 450 \\
\hline 10.00 & 0.02 & 3500 & 109.9 & 70 \\
\hline 10.00 & 0.05 & 3500 & 109.9 & 175 \\
\hline 10.00 & 0.08 & 3500 & 109.9 & 280 \\
\hline 10.00 & 0.1 & 3500 & 109.9 & 350 \\
\hline 10.00 & 0.12 & 3500 & 109.9 & 420 \\
\hline 10.00 & 0.15 & 3500 & 109.9 & 525 \\
\hline 10.00 & 0.02 & 4500 & 141.3 & 90 \\
\hline 10.00 & 0.05 & 4500 & 141.3 & 225 \\
\hline 10.00 & 0.08 & 4500 & 141.3 & 360 \\
\hline 10.00 & 0.1 & 4500 & 141.3 & 450 \\
\hline 10.00 & 0.12 & 4500 & 141.3 & 540 \\
\hline 10.00 & 0.15 & 4500 & 141.3 & 675 \\
\hline 1.10 & & & & \\
\hline
\end{tabular}

Tab. 1. Plan of experiments

\begin{tabular}{|c|c|c|c|c|}
\hline$D$ & $f$ & $n$ & $V c$ & $V f$ \\
\hline$[m m]$ & {$[m m / r o t]$} & {$[r o t / m i n]$} & {$[m / m i n]$} & {$[\mathrm{mm} / \mathrm{min}]$} \\
\hline 10.00 & 0.02 & 3000 & 94.2 & 60 \\
\hline 10.00 & 0.05 & 3000 & 94.2 & 150 \\
\hline 10.00 & 0.08 & 3000 & 94.2 & 240 \\
\hline 10.00 & 0.1 & 3000 & 94.2 & 300 \\
\hline 10.00 & 0.12 & 3000 & 94.2 & 360 \\
\hline 10.00 & 0.15 & 3000 & 94.2 & 450 \\
\hline 10.00 & 0.02 & 3500 & 109.9 & 70 \\
\hline 10.00 & 0.05 & 3500 & 109.9 & 175 \\
\hline 10.00 & 0.08 & 3500 & 109.9 & 280 \\
\hline 10.00 & 0.1 & 3500 & 109.9 & 350 \\
\hline 10.00 & 0.12 & 3500 & 109.9 & 420 \\
\hline 10.00 & 0.15 & 3500 & 109.9 & 525 \\
\hline 10.00 & 0.02 & 4500 & 141.3 & 90 \\
\hline 10.00 & 0.05 & 4500 & 141.3 & 225 \\
\hline 10.00 & 0.08 & 4500 & 141.3 & 360 \\
\hline 10.00 & 0.1 & 4500 & 141.3 & 450 \\
\hline 10.00 & 0.12 & 4500 & 141.3 & 540 \\
\hline 10.00 & 0.15 & 4500 & 141.3 & 675 \\
\hline
\end{tabular}

Tab. 2. Plan of experiments

Based on the results obtained by processing experimental, the dependence graphs was drawing and made between cutting forces and cutting parameter regime, keeping the others parameter constant. For each product considered, depending on the parameters of the cutting conditions, considered in the calculated data, are shown as graphs, the study of parameters influence on the cutting force, component $\mathrm{Fz}$, for drilling biocomposites polymeric products. From the study of graphs, we noted that the cutting regime parameters have a significant influence on the process of cutting.

\section{ANALYSIS OF THE RESULTS}

Figure 3 represent the variation of the cutting forces and their dependence to the parameters of the drilling of the biocomposite polymeric product reinforced with particles of pine wood.

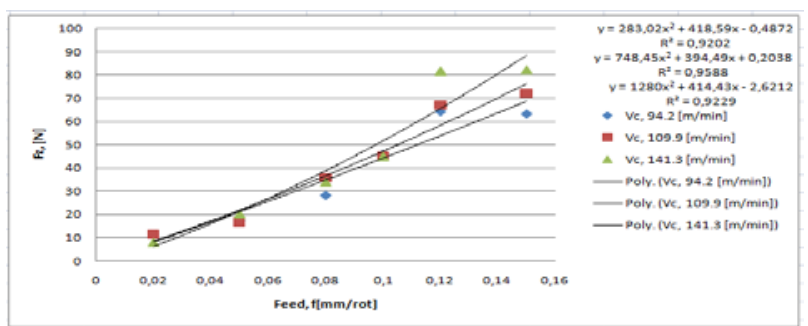

Fig. 3. Shows the variation of axial force as a function of feed rates, for different drilling speeds of the tool $(D=c t)$

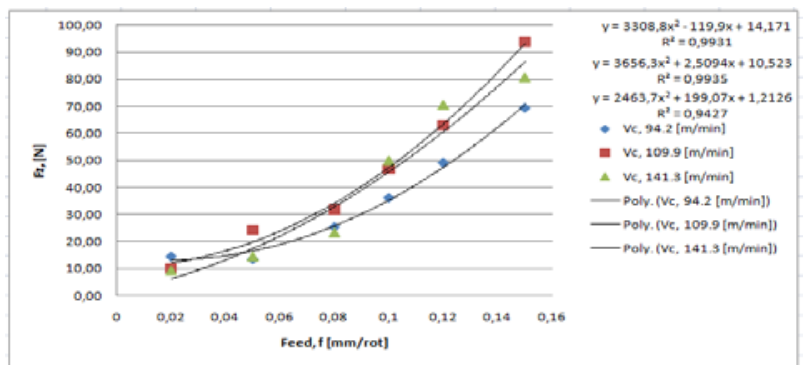

Fig. 4. Shows the variation of axial force as a function of feed rates, for different drilling speeds of the tool $(\mathrm{D}=\mathrm{ct})$
Figure 4 represent the variation of the cutting forces and their dependence to the parameters of the drilling of the biocomposite polymeric product reinforced with particles of oak wood.

\section{CONCLUSIONS}

Analyzing the results obtained from these charts and program data based on biocomposites polymeric product reinforced with fibers of oak wood and pine wood, we can highlight a few conclusions:

-Components of cutting forces are much smaller compared to steel or cast iron made in the case;

-Higher values of the cutting force, component $\mathrm{Fz}$, were obtained when it was processed biocomposites polymer product reinforced with particles of oak;

-Comparative analysis of the two materials the materials based on certain softwood and the reinforced particles of pine wood, are more advantageous in terms of the size of cutting forces;

-To reduce variations of cutting forces was contributed the proper geometry of cutting tools used for research experiments; -Among the cutting parameters of cutting regime the feed rate and cutting speed have a greater influence on the size of the cutting forces.

From the analysis of the variation of the cutting forces for these two types of biocomposite polymeric product (with particles of oak wood and particles of pine wood) the following conclusions can be drawn:

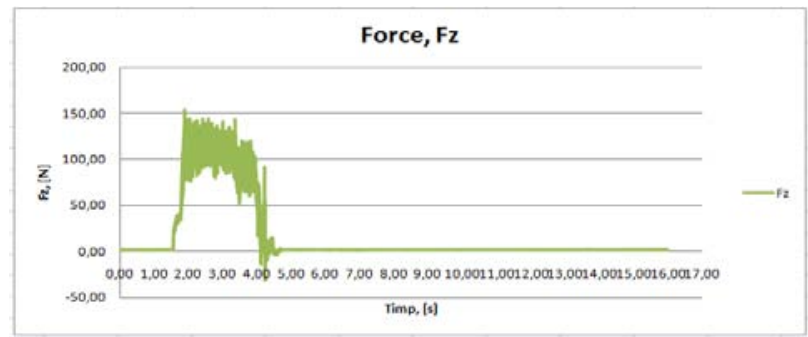

Fig. 5. Variation of the cutting forces for biocomposites polymeric reinforced with particles of oak.

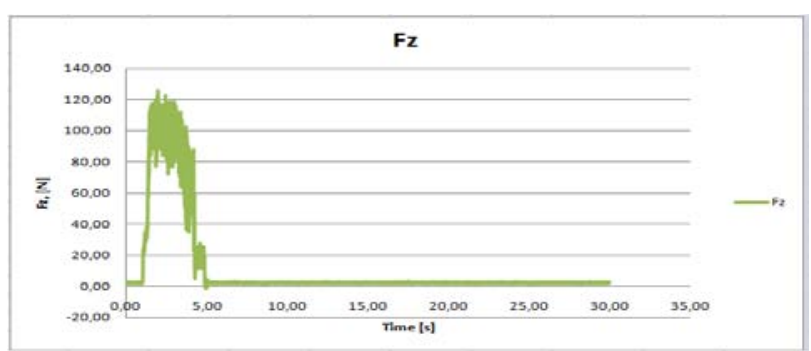

Fig. 6. Variation of the cutting forces for biocomposites polymeric reinforced particles of pine wood

\section{REFERENCES}

Murar, D.; Opran, C.; Bivolaru C. (2011). Research regarding mechanical and structural behavior of polimeric biocomposites products, Proceeding of the International Conference and Exhibition CNC Technologies, pp. 111114, Bucuresti, Romania

Opran, C.; Blajină, O. (2009). Temperature field in EDM of ceramics composites; Annals Of Daaam For 2009\& Proceedings Of The 20th International DAAAM Symposium; Vol. 20, No. 1, pp. 1519-1522, ISSN 17269679,Published By DAAAM International,Viena, Austria

Opran, C.; Vasile, N.; Racicovschi, V.; Mohan, G. (2004) Biostructuri polimerice degradabile in mediul natural, Vasile Goldis University Press, Arad, Romania

Tsai, S.W. (2008). Strength \& life of composites, Editor Aeronautics \& Astronautics Stanford University, SUA

Vlase, A. (2007). Tehnologii de prelucrare pe maşini de găurit, Editura BREN, Bucuresti, Romania 